\title{
Approaches to Accountability in Long-Term Care
}

\section{Démarche de l'obligation de rendre compte dans les soins de longue durée}

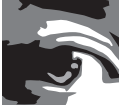 \\ WHITNEY BERTA, MBA, PHD \\ Associate Professor, Institute of Health Policy, Management E Evaluation \\ University of Toronto \\ Toronto, ON \\ AUDREY LAPORTE, PHD \\ Associate Professor, Institute of Health Policy, Management $\mathcal{E}$ Evaluation, University of Toronto \\ Adjunct Scientist, Institute for Clinical Evaluative Sciences \\ Toronto, ON \\ WALTER P. WODCHIS, PHD \\ Associate Professor, Institute of Health Policy Management \& Evaluation, University of Toronto \\ Research Scientist, Toronto Rehabilitation Institute \\ Adjunct Scientist, Institute for Clinical Evaluative Sciences \\ Toronto, ON
}

\begin{abstract}
This paper discusses the array of approaches to accountability in Ontario long-term care (LTC) homes. A focus group involving key informants from the LTC industry, including both for-profit and not-for-profit nursing home owners/operators, was used to identify stakeholders involved in formulating and implementing LTC accountability approaches and the relevant regulations, policies and initiatives relating to accountability in the LTC sector. These documents were then systematically reviewed. We found that the dominant mechanisms have been financial incentives and oversight, regulations and information; professionalism has played a minor role. More recently, measurement for accountability in LTC has grown to encompass an array of fiscal, clinical and public accountability measurement mechanisms. The goals of improved quality and accountability are likely more achievable using these historical regulatory approaches, but the recent rapid increase in data and measurability could also enable judicious application of market-based approaches.
\end{abstract}




\section{Résumé}

Cet article porte sur l'organisation des démarches de l'obligation de rendre compte dans les résidences de soins de longue durée (SLD) en Ontario. Un groupe de discussion formé d'informateurs clés du secteur - des propriétaires ou gestionnaires de centres d'hébergement et de soins à but lucratif ou non - a été réuni pour déterminer qui sont les intervenants impliqués dans la définition et la mise en ouvre des démarches d'obligation de rendre compte ainsi que de la réglementation, des politiques et des initiatives connexes dans le secteur des SLD. Ces documents ont été examinés systématiquement. Nous avons observé que les principaux mécanismes sont les mesures incitatives ainsi que le contrôle financier, la réglementation et l'information; le professionnalisme y a joué un rôle secondaire. Plus récemment, l'évaluation de l'obligation de rendre compte dans les SLD s'est accrue pour inclure une gamme de mécanismes de mesures concernant l'obligation fiscale, clinique et publique. Il serait plus facile d'atteindre les objectifs d'amélioration de la qualité et d'obligation de rendre compte en utilisant ces démarches de réglementation traditionnelles, mais l'accroissement rapide des données et de la mesurabilité pourrait permettre une application judicieuse de démarches propres aux marchés commerciaux.

I n Canada, long-term care (LTC) programs are generally delivered via two distinct channels: communities and facilities. This paper focuses on regulated facilitybased LTC services in Ontario, referred to as LTC homes (LTCHs). LTCHs generally provide a lower level of care than that offered in hospitals; however, some overlap exists. Individuals residing in LTCHs in Canada are those in need of high levels of daily personal care; this may entail supervision or assistance with activities of daily living, 24/7 nursing care or supervision or provision of a secure environment (Williams et al. 2009). Because LTCHs do not fall under the terms of the Canada Health Act, there is no requirement for them to be publicly funded. As is the case for all healthcare services, provincial governments have jurisdiction over which (if any) policies will be applied to these facilities; for example, there is also an extensive, largely unregulated subsector providing "residential care" to privately paying seniors, an activity deemed to fall outside the LTC system, and outside the scope of this paper. As a consequence, the nature, level and availability of institutional LTC varies from jurisdiction to jurisdiction (Berta et al. 2006). Most provinces, including Ontario, have delegated much of the responsibility to regional health authorities.

In Ontario, the provincial government pays for a portion of the costs of institutional LTC, and regional community care access centres (CCACs) have been given responsibility for managing resident admissions and placement to publicly subsidized LTCHs. The governance and ownership of LTCHs is an important feature of this sector. As of April 2012, 57\% of Ontario's 630 LTCHs were for-profit, with a mix of private ownership and board oversight 
among publicly traded, investor-owned companies. Another $26 \%$ were not-for-profit (principally charitable) homes with varying governance structures; the remaining $17 \%$ were municipally owned homes (see also Wyers et al. 2014).

\section{Accountability in Healthcare}

Accountability refers to the imperative to answer to someone (e.g,, a stakeholder, shareholder or overseer) and to demonstrate doing so by meeting the objectives set by them (see Deber 2014, this issue; Emanuel and Emanuel 1996; Fooks and Maslove 2004). Accountability can be complicated by the need to be accountable to multiple parties who may have divergent interests. Accountability is multidimensional; Brinkerhoff $(2003,2004)$ refers to three dimensions. Financial accountability refers to a focus on complying to explicit financial reporting procedures; in healthcare, health service providers are fiscally accountable to payers, which for some services may include the government. Performance accountability refers to a focus on achieving defined or prescribed, measureable outputs; in healthcare, this is generally articulated as clinical accountability and clinical measures/outcomes. The political/democratic accountability dimension refers to fulfilling public trust, and in healthcare equates to public accountability. Specific approaches to accountability - how accountability is exercised - vary. The series of substudies in this Special Issue focused on four main approaches ("policy instruments") that dominate in healthcare (recognizing that these are not mutually exclusive): regulations, the use of financial incentives/expenditures, the provision of performance information to payers and the public and professionalism/stewardship (Deber 2014). We hypothesized that the mix of these approaches would vary by sector, and that the "success" with which they were applied would vary, in turn, as a function of the clarity and feasibility of the policy goals that are set, the fit between these goals and the governance/ownership structures of provider organizations, and the types of goods and services being delivered and their production characteristics.

\section{Accountability Dynamism in Ontario's Long-Term Care Sector}

In most jurisdictions, LTC is stringently regulated (Grunier and Mor 2008; Hollander 1994), and a vital aspect of LTCHs' operations is to ensure adherence to the standards set by government regulators; failure to do so may incur loss of provincial funding or of licensure. In Ontario, the Ministry of Health and Long-Term Care (MOHLTC) regulates and inspects all nursing homes that fall under the terms of the 2007 Long-Term Care Homes Act (LTCHA), and it is responsible for the granting of nursing home licences.

The past several years have been transformational for Ontario's LTC industry. Changes have been wrought that not only affect how Ontario's 630 LTCHs are accountable, but to whom, and the goals of accountability approaches have been expanded from a historical focus on the operational to the aspirational, including support for continuous quality improvement initiatives. Throughout this evolution, the provincial government has maintained a strong oversight of LTCHs in Ontario through legislation and regulatory oversight. 
In 2006, Ontario set up 14 regional local health integration networks (LHINs) with responsibility for managing the flow of provincial funds for specified healthcare services in their regions; these services include hospitals and community care access centres (CCACs). CCACs also commission certain home care professional services (see Steele Gray et al. 2014), and have some responsibility for helping to manage admissions to publicly subsidized LTCH placements. Accordingly, some of the operational aspects of accountability, historically the purview of MOHLTC, were delegated to the LHINs. In particular, the LHINs have been given responsibility for managing accountability agreements with many of the regional bodies (including hospitals) who receive provincial money (see also Kromm et al. 2014).

\section{Methods}

\section{Focus group}

In Fall 2012, we held a focus group discussion with eight key informants from the LTC industry, including representatives of the for-profit $(n=2)$ and not-for-profit $(n=2)$ nursing home subsectors, and health services researchers with experience in examining policy $(n=2)$, performance $(n=1)$ and economic issues $(n=1)$ in Ontario's, and Canada's, LTC industry. Focus group participants were asked to identify all stakeholders involved in the formulation and implementation/execution of accountability approaches; to identify the regulations, accountability policies, programs and initiatives of relevance to Ontario's institutional LTC sector; and to elaborate on their experiences - direct and observed - with the application of these accountability mechanisms. Focus group participants were selected purposively (Patton 2001) in the interests of identifying key informants with adequate knowledge and experience to address our questions. Since the purpose of the focus group was to inform the document review, we do not report on results of the focus group separately in this paper.

\section{Document review}

We then reviewed all current regulations of relevance to the LTC sector, and the documented information relating to accountability policies, programs and initiatives identified by our participants. These are publicly available documents, where regulations are accessible on the government website, and information about current long-term care service accountability agreements (L-SAAs) are posted on several websites. ${ }^{1}$

We also consulted a series of draft L-SAA templates from previous years, some of which can be found on the Ontario Long Term Care Association's website ${ }^{2}$ and on individual LHIN websites.

The numerous acronyms associated with the materials included in our review are summarized in the Appendix (see Appendix at www.longwoods.com/content/23851). 


\section{Results}

Of the four approaches to accountability that are prominent in healthcare generally, the three of particular prominence in the LTC sector are regulation, the use of financial incentives and the provision of performance information to payers and the public; there was far less emphasis on mechanisms related to professionalism/stewardship, in part because LTC relies heavily on personal support workers and other providers who are not regulated (see Baumann et al. 2014). Control is dispersed; regulations are standardized by MOHLTC, but LHINs are responsible for the payments to LTCHs, and financial accountability and accountability for inspection findings are included within three-year service-agreement contracts (L-SAAs). ${ }^{3}$ Two other accountability mechanisms are aligned with the exhortation governing instrument; these include information included in public reporting of LTCH quality of care on a public website maintained by Health Quality Ontario (HQO) and accreditation. While all Ontario nursing homes must be licensed, most are also accredited by Accreditation Canada, ${ }^{4}$ a nongovernmental entity that evaluates nursing homes as well as other healthcare providers (see Mitchell et al. 2014) and by the Commission on Accreditation of Rehabilitation Facilities (CARF). ${ }^{5}$ Public reporting at HQO began as a voluntary exercise in 2009 but became mandatory in 2013. Accreditation is voluntary.

\section{Regulatory approaches to accountability in LTC}

\section{THE LONG-TERM CARE HOMES ACT, 2007 (LTCHA)}

Effective July 2010, the LTCHA replaced the three discrete acts that had governed Ontario's different models of LTCHs: the Nursing Homes Act (for-profit homes), the Charitable Institutions Act (not-for-profit homes) and Homes for the Aged and Rest Homes Act (municipal homes). In addition to reinforcing the notion that LTCHs must be places where residents feel safe, secure and comfortable and receive care that meets their needs, the LTCHA enforces building codes and operational procedures more stringently than these previous Acts. Under the LTCHA, the Resident's Bill of Rights has been extended such that every home must have a Residents' Council, a Family Council and a mission statement developed in collaboration with these councils. Every resident must have a plan of care covering all aspects of care, with clearly defined goals and direction to staff on how they will be achieved, including medical, nursing, personal support, nutritional, dietary, recreational, social, restorative, religious and spiritual care, which must be reviewed and revised at least every six months. Significantly, the LTCHA requires that assessment instruments are applied in five clinical areas that have long been linked to the quality of resident care (Richardson et al. 2001): falls, skin and wound care, continence care and bowel management, responsive behaviours (a term referring to challenging behaviours exhibited by residents with dementia) and pain management. 


\section{REVISING COMPLIANCE INITIATIVES AS PER THE LTCHA AND NEW QUALITY} IMPROVEMENT AIMS

In April 2008, MOHLTC's LTCH Compliance Management Program was redesigned to align with the LTCHA. The program ensures that LTCHs are meeting the standards and criteria set out in MOHLTC policy and licensing agreements, and the L-SAA. The new compliance system also responds to public and sector interest in improving residents' safety, and their quality of care and life, through continuous quality improvement. Compliance inspections are more collaborative and consultative, and now include a Resident Quality Inspection (RQI) that engages residents, families and staff in structured interviews regarding their care experiences.

Unannounced random inspections have been implemented; they use mandatory inspection protocols that are based on the most problematic areas as reflected in complaints (these include admission processes, dining, infection prevention and control, medication management and charges to residents). As a result of Ontario's legislative changes and the new Compliance Management Program, all issues of non-compliance are identified and documented in an inspection report. In the event of non-compliance, a more in-depth inspection process is undertaken that targets the areas of care quality described in the LTCHA and regulations. Past history of compliance, and the severity and the scope of the non-compliance, are used to determine actions; these may range from requiring a response plan, to fines, to closure of the facility to new admissions or, in extreme cases, closure of the LTCH.

With the LTCHA, the provincial government has maintained a high degree of regulatory oversight with the policy goal of ensuring the safety of residents in LTCHs. This regulation is classified as a high-coercion policy instrument; compliance is required for licence renewal. MOHLTC also continues to determine funding levels, licensing and approval of LTC beds, and approves changes of ownership, sales and amalgamations for purposes of licensing, as well as the selection of a third-party management company in the event of a bankruptcy.

\section{Financial accountability approaches in LTC}

\section{DEVOLUTION OF FISCAL ACCOUNTABILITY TO LOCAL HEALTH INTEGRATION} NETWORKS (LHINs)

While the precise powers of LHINs are still contentious, on paper they have a mandate to plan, fund and integrate healthcare services for more efficient and effective care in their regions. LTCH funding is provided through four funding envelopes paid by the province but managed by the LHINs: (a) nursing and personal care (NPC), from which the majority of LTCH staff are paid, including nursing and personal care staffing, and medical/nursing supplies and equipment; (b) program and support services (PSS), from which certain recreation staff and expenditures are covered, as well as therapeutic services, pastoral care, staff training and volunteers; (c) raw food; and (d) other accommodations, from which room and board costs are expensed, including housekeeping, laundry, dietary services, administration and building/property operations and maintenance, mortgage payments and taxes. Residents pay a 
co-payment as a portion of the full funding levels, the amount of which is set by the province and is dependent upon the type of room (e.g., private) and the resident's ability to pay. The NPC, PSS and raw food envelopes are "reconcilable," meaning that MOHLTC's Financial Management Branch compares actual spending to allowable spending in these envelopes. Unspent funds must be returned to the LHIN, although overexpenditures in these envelopes can be balanced with surpluses from the other accommodation envelope (which is nonreconcilable, meaning that excess revenues in this envelope can be retained by the LTCH). The Financial Management Branch retains responsibility for reviewing the audited annual report (AAR) and Revenue/Occupancy Report, and administering the subsidy calculation worksheet, on behalf of the LHINs. This very tight management of financing provides a strong incentive to manage budgets closely but does not incentivize rewarding quality or performance.

L-SAAs encapsulate the terms of the service agreements between the LHINs and the LTCHs. While largely operational in nature with a focus on financial reconciliation and adherence to compliance inspection standards, the next generation of L-SAAs is expected to focus more on performance management and achieving performance goals. While LHINs do not have the authority to establish LTCH resident care standards (this responsibility still remains within the domain of MOHLTC), LHINs may set performance targets for LTCH indicators in the L-SAA.

Beyond administering the L-SAAs, LHINs are also responsible for reviewing and monitoring LTCH occupancy rates, as well as placement refusal trends, transfer request trends and wait list profiles. LHINs further monitor bed utilization, performance and expenditures, and recover and reallocate operating funds through an annual reconciliation process facilitated through the Revenue/Occupancy Report.

\section{ALIGNING PERFORMANCE MEASUREMENT SYSTEMS WITH NEW FISCAL} ACCOUNTABILITY IMPERATIVES

Advances in both clinical and fiscal accountability in Ontario's LTC sector are being supported by the introduction of two initiatives that enhance the measurability of financial performance and resident clinical outcomes: the full-scale implementation of the Resident Assessment Instrument - Minimum Data Set (RAI-MDS) and the introduction of the Long-Term Care Homes Ontario Healthcare Reporting Standards/Management Information Systems.

Full-scale implementation of the RAI-MDS in Ontario's LTCHs began in 2010. RAIMDS provides a comprehensive functional and clinical assessment of residents, and is intended for use in resident care planning and evidence-based decision-making. RAI-MDS data are used to provide evidence-based indicators for compliance inspection purposes and are also used by HQO to publicly report quality care indicators at the home level. RAI-MDS data are also used to calculate LTCHs' case mix index (CMI) based on the Resource Utilization Groups (RUGs) case mix grouping system. ${ }^{6}$ 
The second major initiative relating to performance measurement is the Ontario Healthcare Reporting Standards/Management Information System (OHRS/MIS), which provides LTCHs with a standardized financial and statistical framework for data collection processes; benchmarks with peers based on indicator tools and provincial comparative reports; the ability to track trends; improvements to transparency and performance accountability; and the means by which to demonstrate service efficiency and effectiveness. The OHRS/ MIS complies with the Canadian Institute for Chartered Accountants (CICA) and Generally Accepted Accounting Principles (GAAP). Following a pilot phase in 2009, all LTCHs have implemented OHRS reporting.

\section{Public accountability approaches in LTC}

\section{GOVERNMENT ACCOUNTABILITY TO THE PUBLIC}

MOHLTC leads or supports a number of initiatives intended to ensure accountability to the public. The Ministry's Reports on Long-Term Care website ${ }^{7}$ provides basic information on every LTCH operating in Ontario (ownership, management, size, accreditation status) and the results of compliance inspection reports including critical incidents, complaints and other inspection outcomes. Concurrent with the introduction of the LTCHA and the public reporting initiative, MOHLTC has improved the process for complaints reporting through a tollfree Long-Term Care ACTION Line (complaints may also be made in writing or by e-mail).

\section{PUBLIC PERFORMANCE REPORTING}

In addition to the public reporting website supported by MOHLTC, HQO provides an annual report on the health system and includes indicators related to nine areas of health system performance, assessing healthcare organizations on the basis of whether they are accessible, effective, safe, patient-centred, equitable, efficient, appropriately resourced, integrated and focused on the population. In its annual report, HQO currently tracks LTCH indicators associated with six of these domains (see Table 1). In addition to the QMonitor, HQO maintains its own LTC public reporting website $e^{8}$ and offers performance data for each LTCH in Ontario relative to provincial averages for falls, incontinence, pressure ulcers and restraint use. 
TABLE 1. Areas of performance in HQO's QMonitor Annual Report on Ontario's healthcare system

\begin{tabular}{|c|c|c|}
\hline Area of Performance & & Indicator \\
\hline Accessible & Wait Times & $\begin{array}{l}\text { Median number of days to long-term care home } \\
\text { placement }\end{array}$ \\
\hline \multirow[t]{5}{*}{ Effective } & Incontinence* & $\%$ of residents with worsening bladder control \\
\hline & Activities of Daily Living (ADLs) & $\begin{array}{l}\% \text { of residents with increasing difficulty carrying out } \\
\text { normal everyday tasks }\end{array}$ \\
\hline & Cognitive Function & $\begin{array}{l}\% \text { of residents whose language, memory and } \\
\text { thinking abilities have recently decreased }\end{array}$ \\
\hline & Pain & $\%$ of residents with pain that got worse recently \\
\hline & Emergency Department Visits & $\begin{array}{l}\text { \# of emergency department visits due to an } \\
\text { ambulatory care-sensitive condition per I } 00 \text { LTC } \\
\text { residents per year }\end{array}$ \\
\hline \multirow[t]{4}{*}{ Safe } & Falls* & $\%$ of residents who had a recent fall \\
\hline & Pressure Ulcers* & $\begin{array}{l}\% \text { of residents who had a pressure ulcer that } \\
\text { recently got worse }\end{array}$ \\
\hline & Restraints* & $\%$ of residents who were physically restrained \\
\hline & Medication Safety & $\begin{array}{l}\text { \% of residents aged } 65 \text { years or older prescribed a } \\
\text { drug that should never be used among the elderly } \\
\text { per } 100,000 \text { residents aged } 65 \text { years or older } \\
\text { per year }\end{array}$ \\
\hline Appropriately Resourced & Health Human Resources & \# of injuries per I00 LTC workers per year \\
\hline $\begin{array}{l}\text { Focused on Population } \\
\text { Health }\end{array}$ & Infections & $\%$ of long-stay residents with new infections \\
\hline
\end{tabular}

* Also reported on the public reporting website.

\section{ACCREDITATION}

While all Ontario LTCHs must be licensed through MOHLTC, most also voluntarily seek accreditation through Accreditation Canada, a non-governmental entity that evaluates nursing homes and assists them in meeting regulations and compliance (see also Mitchell et al. 2014).

In 2008, Accreditation Canada introduced a new program, Qmentum, which emphasizes health system performance, risk prevention planning, client safety, performance measurement and governance. Extensive feedback is synthesized from a LTCH's clients, surveyors, board members and staff to produce tailored required organizational practices (ROPs) to help them meet their performance goals. Qmentum surveyors debrief administrators and staff members on their findings, and provide evaluation results via a client organization portal supported by Accreditation Canada. One key feature of this portal is the quality performance roadmap (QPR), which displays the organization's progress. The QPR is intended to be used as a quality improvement tool. It allows organizations to submit evidence of action to Accreditation Canada. 


\section{Discussion}

\section{Approaches to accountability in Ontario's LTC sector}

The three dominant approaches to accountability being used in Ontario's LTC sectors are regulation, financial incentives and the provision of performance information to payers and public.

Regulations are enacted by MOHLTC and enforced through compliance and unannounced inspections, and through another layer of oversight, the regional health authorities (LHINs). The stringency of regulatory oversight is likely associated with the perceived vulnerability of LTC residents who are commonly medically, physically or cognitively impaired and less able to reliably use formal approaches to raise concerns about the quality of care provided in LTCHs. The high degree of regulatory stringency suggests that policy makers do not believe that other mechanisms, such as information and professionalism, are sufficient to achieve the policy goal of the sector.

Financial incentives and oversight in LTC have historically focused on cost containment and case mix adjusted standardized payment for residents, with the strong emphasis on financial oversight perhaps due in part to the dominance of for-profit providers in the sector. The devolution of more focused objectives regarding resident safety through the 2007 LTCHA reflects to some degree the view that oversight should occur as closely as possible to the location of care delivery. Nevertheless, the focused objectives still tend to be highly weighted towards financial measures, albeit with increased emphasis on performance assessment.

The extent and sophistication of information directed towards patients and providers is evolving and is accessible online, facilitated by inspection reports made available from MOHLTC and public reporting by HQO. Information availability and use is still fairly limited, however, and we see this as one of the most promising areas for improved accountability and performance in LTC. The recent greater involvement of patients and their families and the development of a complaints accountability infrastructure appear to be mechanisms that have been employed within the LTC sector to increase the flow of information about the quality of care being provided at facilities across the province.

Recently, there has been an effort to align these approaches. For example, with the articulation of policy goals that focus on residents' quality of life and outcomes, cemented in the Long-Term Care Homes Act, 2007, regulatory approaches are augmented by performance improvement mechanisms such as the RAI-MDS. The RAI-MDS, for example, has facilitated a shift from case mix payments based on age and sex adjustment to payments based on more detailed health indicators (e.g., cognitive and functional limitations) that better reflect the care needs of the aged. By tying funding resources more closely to patient needs, the disincentives that existed for assuming the care of highly complex patients in the LTC sector are markedly diminished. This specific example illustrates an important synergy between "old" financial accountability approaches, new policy goals articulated through new regulation, and the operationalization of these goals using new performance accountability approaches. 
The role of professionalism is far less emphasized in the LTC sector compared to others. This finding is likely attributable in large part to the relatively low involvement of professional staff in care delivery in LTC homes. There is minimal physician oversight, with managerial and clinical roles carried out predominantly by registered nurses (RNs) and registered practical nurses (RPNs). Most of the direct resident care ( $\sim 80 \%)$ is delivered by unregulated workers - healthcare aides (HCAs) and personal support workers (PSWs). While professionalism as traditionally constructed may play less of a role in LTC, there may be a future for unions to play a role in ensuring standards of care. The Canadian Union of Public Employees (CUPE) represents 24,000 workers, and the Canadian Auto Workers Union (CAW) represents 16,000 workers in Ontario's LTC sectors.

\section{Appropriateness of accountability approaches in Ontario's LTC sector}

In terms of production characteristics, publicly subsidized LTC services in Ontario have limited contestability (that is, market entry is highly restricted) as a consequence of licence requirements and the limits imposed by the Province on the number of LTC "spaces" it will pay for. Measurability is somewhat problematic (particularly for "softer" outcomes) but has been enhanced with the comprehensive clinical information and public reporting based on the RAI-MDS data that include not only adverse clinical outcomes as currently measured but also health-related quality-of-life measures (including cognitive and physical function, engagement and participation in activities, pain and emotional health). Such public reporting of a larger set of quality indicators and a star-rating system for consumers based on RAI-MDS quality indicators and state inspection results is being used in the US to improve market functioning. Complexity is difficult to assess, although most services must be delivered within the LTCH.

The largest of these issues is contestability, with greater allowance for market entry and exit, suggesting that a less stringent regulatory approach might be successful. The governance of LTC is highly varied and includes a large proportion of for-profit enterprises and corporations with some cottage industry solo private operators, and may require strengthening to enable the success of a less regulatory approach. This extensive variety of governance and ownership models in the LTC sector suggests that the application of policy instruments will likely have non-uniform effects across the models. The appearance of low trust in the LTC sector is potentially affected by the high vulnerability of the population, as well as media reports of poor quality and occasional avoidable deaths in LTCHs.

\section{Conclusion}

In sum, our assessment of accountability mechanisms in the LTC sector suggests that improving quality and accountability is likely more responsive to regulatory approaches, but could also be enabled through judicious market-based approaches. For the latter approach to succeed, expanded and strengthened public reporting of quality, including clinical quality and 
quality-of-life or resident experience information, would be necessary to improve the capacity of individuals to make informed choices about their selection of LTCH. Success of the market-based approach would clearly depend on the complexity of cases, and may be less feasible because an emphasis on care in the community means that those admitted to such homes are increasingly frail.

\section{Acknowledgements}

This study was funded by CIHR-PHSI Grant (CIHR Grant Number PHE-101967).

Our sincere thanks to Ms. Jenny Armour for her assistance in reviewing the documents referred to in this paper, and to Mr. Kevin Walker for his assistance in augmenting statistical data regarding sector characteristics.

Correspondence may be directed to: Whitney Berta, Associate Professor, Institute of Health Policy, Management \& Evaluation, University of Toronto, Health Sciences Building, 155 College St., Suite 425, Toronto, ON M5T 3M6; tel.: 416-946-5223; e-mail: whit.berta@utoronto.ca.

\section{Notes}

1. See, in particular, www.lhincollaborative.ca/Page.aspx?id=1968, www.lhincollaborative.ca/ lsaa/lsaahome.aspx and www.health.gov.on.ca/en/public/programs/ltc/lsaa_policies.aspx.

2. See http://oltca.com/funding-policy-bulletin-archives.

3. See www.lhincollaborative.ca/lsaa/lsaahome.aspx.

4. See www.accreditation.ca/en.

5. See www.carf.org/Programs/AS.

6. See www.cihi.ca.

7. See www.health.gov.on.ca/en/public/programs/ltc/26_reporting.aspx.

8. See www.hqontario.ca/public-reporting/long-term-care.

\section{References}

Baumann, A., P. Norman, J. Blythe, S. Kratina and R.B. Deber. 2014. Accountability: The Challenge for Medical and Nursing Regulators. Healthcare Policy 10(Special Issue): 121-131.

Berta, W., A. Laporte, D. Zarnett, V. Valdmanis and G. Anderson. 2006. “A Pan-Canadian Perspective on Institutional Long-Term Care." Health Policy 79(2-3): 175-94.

Brinkerhoff, D. 2003 (January). Accountability and Health Systems: Overview, Framework and Strategies. Bethesda, MD: PHR Plus, Abt Associates Inc., U.S. Agency for International Development. Retrieved March 25, 2014. <http://www.who.int/management/partnerships/accountability/AccountabilityHealthSystemsOverview.pdf>. Brinkerhoff, D.W. 2004. “Accountability and Health Systems: Toward Conceptual Clarity and Policy Relevance." Health Policy and Planning 19(6): 371-79. doi: 10.1093/heapol/czh052.

Deber, R.B. 2014.“Thinking about Accountability.” Healthcare Policy 10(Special Issue): 12-24.

Emanuel, E.J. and L.L. Emanuel. 1996. "What Is Accountability in Health Care?" Annals of Internal Medicine 124(2): 229-39. doi: 10.7326/0003-4819-124-2-199601150-00007.

Fooks, C. and L. Maslove. 2004. Rhetoric, Fallacy or Dream? Examining the Accountability of Canadian Health Care to Citizens. Ottawa: Canadian Policy Research Networks. Retrieved March 25, 2014. <http://www.cprn.org/doc. cfm?doc $=549>$. 
Grunier, A. and V. Mor. 2008. “Nursing Home Safety: Current Issues and Barriers to Improvement.” Annual Review of Public Health 29: 369-82. doi: 10.1146/annurev.publhealth.29.020907.090912.

Hollander, M.J. 1994. The Costs and Cost-Effectiveness of Continuing Care Services in Canada. Ottawa: Queen's-University of Ottawa Economic Projects-Working Paper No. 94-10.

Kromm, S.K., G.R. Baker, W.P. Wodchis and R.B. Deber. 2014. “Acute Care Hospitals' Accountability to Provincial Funders." Healthcare Policy 10(Special Issue): 25-35.

Mitchell, J.I., W. Nicklin and B. MacDonald. 2014. “The Accreditation Canada Program: A Complementary Tool to Promote Accountability in Canadian Healthcare." Healthcare Policy 10(Special Issue): 150-53.

Patton, M.Q. 2001. Qualitative Research and Evaluation Methods (3rd ed.). Newbury Park, CA: Sage Publications.

Richardson, J., J. Moreland and P. Fox. 2001. “The State of Evidence-Based Care in Long-Term Care Institutions: A Provincial Survey." Canadian Journal on Aging 20(3): 357-72. doi: 10.1017/S0714980800012824.

Steele Gray, C., W. Berta, R.B. Deber and J. Lum. 2014. "Home and Community Care Sector Accountability." Healthcare Policy 10(Special Issue): 56-66.

Williams, A.P., D. Challis, R. Deber, J. Watkins, K. Kuluski, J. M. Lum et al. 2009.“Balancing Institutional and Community-Based Care: Why Some Older Persons Can Age Successfully at Home While Others Require Residential Long-Term Care." Healthcare Quarterly 12(2): 95-105. doi: 10.12927/hcq.2009.3974.

Wyers, L., B. Gamble and R.B. Deber. 2014. "Accountability in the City of Toronto's 10 Long-Term Care Homes." Healthcare Policy 10(Special Issue): 99-109. 